\title{
Migrações internacionais motivadas por estudo: uma análise sociodemográfica dos estudantes estrangeiros radicados no Brasil
}

\section{Resumo}

A mobilidade motivada por estudo se caracteriza como um tipo de movimento populacional que vem ganhando força na contemporaneidade, principalmente em função da existência de convênios que favorecem o intercâmbio de estudantes. No Brasil, especificamente, a atuação desse programa tem favorecido a inserção de vários estudantes estrangeiros nas instituições de estudos superiores (IES) públicas e privadas do País. Considerando a importância desse novo tipo de mobilidade da população, bem como as novas características dos atores envolvidos, objetiva-se, a partir dessa discussão, analisar suas características sociodemográficas. Para alcançar este objetivo, desenvolveu-se uma análise descritiva com base nos microdados do Censo do Ensino Superior 2010. Os resultados dessa análise empírica demonstraram que consideráveis diferenciações sociodemográficas entre tais estudantes, principalmente quando se comparam os que são contemplados pelo Programa de Estudante Convênio de Graduação (PEC-G), com os que fazem parte de outros convênios ou outras formas de ingresso.

Palavras-chave: Mobilidade; Estudantes; Convênios; Perfil Sociodemográfico.

\author{
Ricardo Ojima \\ Doutor em Demografia pela \\ Universidade Estadual de Campinas. \\ Professor da Universidade Federal do \\ Rio Grande do Norte - Brasil. \\ ricardo.ojima@gmail.com \\ Moisés Alberto Calle Aguirre \\ Doutor em Demografia pela \\ Universidade Federal de Minas Gerais. \\ Professor da Universidade Federal do \\ Rio Grande do Norte - Brasil. \\ calle@ccet.ufrn.edu

\section{Bruno Lopes da Silva} \\ Mestrando em Demografia pela \\ Universidade Federal do Rio Grande do \\ Norte - Brasil. \\ blsilva1986@bol.com.br

\section{William de Mendonça Lima} \\ Mestrando em Demografia pela \\ Universidade Federal do Rio Grande do \\ Norte - Brasil. \\ lima_william@ymail.com
}

\section{Para citar este artigo:}

OJIMA, Ricardo; AGUIRRE, Moisés Alberto Calle; SILVA, Bruno Lopes da; LIMA, William de Mendonça. Migrações internacionais motivadas por estudo: uma análise sociodemográfica dos estudantes estrangeiros radicados no Brasil. Revista PerCursos. Florianópolis, v. 15, n.28, p. 166 189. jan./jun. 2014.

DOI: $10.5965 / 1984724215282014166$

http://dx.doi.org/10.5965/1984724215282014166 


\title{
International migration motivated by study: a sociodemographic analysis of foreign students in Brazil
}

\begin{abstract}
The study is motivated by mobility characterized as a kind of population movement that is gaining strength in contemporary times, mainly due to the existence of agreements that promote the exchange of students. In Brazil, specifically, the performance of this program has favored the insertion of several foreign students in public and private institutions in the country. Thus, considering the importance of this new type of population mobility in contemporary as well as new characteristics of the actors involved, the goal is to leave this discussion to analyze the sociodemographic characteristics of foreign students living in Brazil. To achieve this goal developed a descriptive analysis based on microdata from the 2010 Census of Higher Education. Results of this empirical analysis demonstrated that there are significant sociodemographic differences between these students, especially when comparing those contemplated by PEC-G, with those who are part of other covenant or other forms of entry.
\end{abstract}

Keywords: mobility; students; covenants; Sociodemographic profile. 


\section{Introdução}

Os estudos sobre as migrações envolvem uma diversidade de abordagens teóricas ligadas às diferentes áreas interessadas na discussão dessa temática. Além de apresentar um amplo espectro de enfoques teóricos, a análise dos processos migratórios, em sua completude, envolve também diferentes motivações, que variam entre os indivíduos. Apesar do predomínio de motivações de cunho econômico (OLIVEIRA e JANNUZZI, 2005), a configuração de um fluxo migratório também pode estar associada a outros aspectos, como a migração motivada por questões educacionais, até mesmo nos casos dos que migram além de suas fronteiras de seu país para cursar uma graduação em outro.

Vale ressaltar que, em muitos países, este tipo de movimento populacional é estimulado pela celebração de convênios interinstitucionais que atuam no ${ }^{1}$ sentido de viabilizar e selecionar os estudantes que terão a oportunidade de se graduar em outra nação. Dentre esses convênios, destaca-se o Programa de Estudante Convênio de Graduação (PEC-G), que busca oferecer oportunidades de formação superior a cidadãos de países em desenvolvimento, desde que tenham acordos educacionais ou culturais com o Brasil (BRASIL, 2014). Este programa é um dos principais mecanismos de inserção de estudantes migrantes no ensino superior brasileiro, principalmente os oriundos de países africanos e sul-americanos. Além desse programa, uma série de outras iniciativas tem sido desenvolvida no intuito de facilitar a mobilidade de estudantes, tanto por órgãos públicos quanto por órgãos privados. Ressalte-se, também, que nessa mobilidade existem pessoas que não estão sendo beneficiadas por nenhum tipo de convênio; trata-se de indivíduos que vieram estudar no Brasil por conta própria, sem receber ajuda de natureza pública ou privada.

Admitida essa mobilidade e a intensificação nos últimos anos da presença de estudantes estrangeiros no Brasil, é objetivo do presente trabalho analisar seu perfil sociodemográfico. Para isso, após uma discussão da literatura sobre migrações

\footnotetext{
${ }^{1}$ Trabalho desenvolvido no âmbito do Programa Observatório da Educação - Capes. Projeto: "O habitus de estudar: construtor de uma nova realidade na educação básica da Região Metropolitana de Natal - RN".
} 
internacionais e intercâmbio educacional, analisaram-se os dados obtidos junto ao Censo do Ensino Superior 2010.

A discussão se estrutura segundo três seções: a primeira procura fazer uma abordagem sobre o marco teórico referente aos processos migratórios associados à educação, dando ênfase aos estudos desenvolvidos no Brasil. Em seguida, procura-se discutir as ações governamentais de incentivo à migração de estudantes, mais precisamente a política de favorecimento ao intercâmbio de estudantes. Na terceira, discute-se o perfil sociodemográfico dos estudantes estrangeiros radicados no Brasil.

\section{Algumas abordagens sobre migração e educação}

A mobilidade populacional é um fenômeno que tem despertado o interesse de várias áreas do conhecimento, como a economia, a demografia, a geografia, a antropologia, entre outras. Todas elas vêm buscando, ao longo do tempo, explicações que proporcionem uma melhor compreensão desse processo, complexo e multifacetado. O entendimento teórico-conceitual da complexidade que envolve os estudos sobre mobilidade espacial da população é de fundamental importância para quaisquer análises que se pretendam fazer.

Em termos gerais, a migração pode ser entendida como a mudança permanente ou semipermanente de residência dentro de um determinado intervalo de tempo. Quando não atende a essa condição temporal de mudança permanente de residência, o movimento populacional não se caracteriza como migração propriamente dita. Um exemplo de movimento populacional não permanente é a mobilidade empreendida por estudantes estrangeiros que se deslocam para outros países em busca de oportunidades educacionais. No caso de alguns programas de cooperação educacional, exige-se do estudante que retorne a seu país de origem após conclusão do curso, para que possa atuar em iniciativas políticas e socioculturais e, com isso, contribuir para a melhoria da qualidade de vida de sua população (LEE, 1980; RIGOTTI, 2013; PORTES, 2004; DESIDÉRIO, 2006). 
Em que consiste uma mudança permanente de residência? Um dos critérios utilizados pelos convênios de intercâmbio estudantil torna obrigatório o retorno do indivíduo ao país de origem após a conclusão dos estudos. Essa modalidade de deslocamento populacional, por isso, não deveria ser tratada como migração. Mas viver por três ou quatro anos em outro país, em muitos casos, pode representar uma mudança de residência muito mais prolongada do que muitas migrações não submetidas aos constrangimentos de um convênio estudantil. Por exemplo, as tentativas de começar uma nova vida no exterior frustradas, acusam retorno em menos de um ano, mesmo que inicialmente fosse intencional uma mudança permanente.

Não se trata aqui de desconfigurar o conceito de migrante usualmente utilizado, mas de dar um tratamento mais substantivo a uma modalidade de deslocamento populacional que é importante sob diversos aspectos e que, mesmo pressupondo uma temporalidade intencional mais curta e predefinida, não descaracteriza um significativo processo social, econômico e político. Destaca-se, ainda, a potencial quebra do pacto de retorno obrigatório ao país de origem que, quando ocorre, efetivamente se caracteriza como migração.

Diante disso, estudar as diferentes modalidades de mobilidade empreendidas por uma determinada população exige um estudo amplo e detalhado para que se possa dar conta de sua complexidade analítica, tendo em vista as inúmeras dificuldades de se apreender suas mais variadas intencionalidades e recortes. Dentre as dificuldades, uma que chama atenção é a que envolve o aspecto motivacional. Considerando o processo migratório, percebe-se que normalmente as razões que influenciam a mudança permanente no local de residência só podem ser analisadas no caso de indivíduos “sobreviventes", ou seja, não pode ser captada a informação daqueles que reemigraram ou morreram antes do momento da coleta da informação (MARTINE, 1980).

Dito isso, é importante salientar que a análise das motivações pode variar de acordo com as diferentes perspectivas teóricas. Por exemplo, a teoria microeconômica neoclássica tende a considerar que "os indivíduos são seres racionais, capazes de ordenar hierarquicamente suas preferências e de realizar cálculos racionais relacionados a alternativas, visando maximizar a utilidade de suas escolhas" (SANTOS, BARBIERI, 
CARVALHO et al., 2010). Nessa perspectiva, o indivíduo é o gestor de sua própria vida, sendo capaz de decidir o local onde irá estabelecer residência e onde irá exercer suas habilidades profissionais, buscando desfrutar de melhores condições de vida.

Mas também seria possível entender as motivações a partir de outras abordagens teórico-metodológicas. O campo da sociologia, por exemplo, entende as migrações como um mecanismo fundamental no processo de transição da sociedade tradicional para a moderna, constituindo-se, assim, em ferramenta de mudança social, cultural e psicossocial, tanto individual, quanto coletiva, dentro do desenvolvimento da sociedade moderna (BRITO, 2009). Com base nesse contexto, é importante salientar que o processo de transição e de mudanças que caracteriza a passagem de uma sociedade tradicional para outra, moderna, conforme destacado anteriormente, apresenta algumas contradições, principalmente no que diz respeito às desigualdades socioespaciais, as quais têm contribuído, muitas vezes, para a marginalização do migrante em relação a determinados setores da sociedade.

O processo migratório também pode ser analisado de uma perspectiva antropológica, ou cultural. Por tal interpretação, a migração poderia ser entendida como um processo cultural e familiar, visto que em determinadas situações a família toda participa do processo migratório, constituindo, assim, uma rede de interações sociais entre si que facilita a integração na região. Estas redes sociais se caracterizam pela presença de familiares ou amigos no lugar de destino, podendo constituir um dos prérequisitos necessários à adaptação do indivíduo. Assim, a existência desses laços de parentesco ou de-amizade que conectam migrantes antigos e migrantes novos, área de origem e área de destino, tende a diminuir os riscos e a aumentar os benefícios para o indivíduo ao se instalar no seu destino. No caso dos estudantes estrangeiros, nem todos possuem esses vínculos sociais nos lugares de destino, fazendo com que o seu processo de adaptação adquira mais complexidade, aliado ao preconceito que muitos encontram quando se relacionam com alguns nativos (BRITO, 2009; ABAD, 2002; KALY, 2001; GUSMÃO, 2008; MUNGOI, 2006).

Estas perspectivas teóricas podem, até certo ponto, ser utilizadas para a análise da migração no contexto de um país, como, por exemplo, o Brasil. Todavia, além da 
existência desse embasamento teórico, vale salientar que outros elementos devem ser considerados, tais como a escala espacial de análise (migração interna ou migração internacional); a temporalidade com que se realiza esse fluxo migratório e a tipologia ocupacional desses migrantes (trabalhadores assalariados, camponeses, estudantes, etc.).

Dentro dessas variáveis, pode-se afirmar que o processo de migração no Brasil apresenta um longo processo histórico que começou com os portugueses, no âmbito da colonização e, posteriormente, com italianos, alemães e japoneses (BARRETO, 2001). O processo perdurou durante grande parte da história do País, de certa forma até estimulando outras correntes migratórias a se direcionar para o território brasileiro.

Dentre os diversos fluxos de imigrantes, vale destacar, desde o final do século passado e início deste, a presença de latino-americanos provenientes de países como Argentina, Paraguai, Chile e Uruguai. Nas últimas três décadas, o Brasil tem se inserido no contexto das migrações internacionais latino-americanas, consolidando-se enquanto área de expansão dessa modalidade de deslocamento populacional, com destaque para as modalidades de tipo fronteiriço - o caso dos países que constituem o Mercosul (BAENINGER, 2008). Também merece destaque o considerável contingente de peruanos e bolivianos.

O perfil do migrante desses países, informação captada por meio dos censos demográficos, permite identificar certo nível de seletividade de-parte dele. De forma geral, seu nível de escolaridade e inserção no mercado de trabalho é bastante favorável, embora se possam fazer algumas ressalvas. Com exceção dos paraguaios e bolivianos que apresentavam maior contingente de pessoas entre os indivíduos com menor escolaridade entre os estrangeiros dos países acima citados -, argentinos, uruguaios, peruanos e chilenos reforçam o contingente de imigrantes no Brasil com médio e alto nível de escolaridade (média de 9 a 15 anos de estudo) (BAENINGER, 2008).

Além disso, é importante deixar claro que a migração de estrangeiros para o Brasil, na contemporaneidade, não se restringe aos fluxos que ocorrem em escala sulamericana. Constata-se o surgimento de novas tendências e de novas motivações em tal 
processo de, tendo como um dos principais exemplos disso a mobilidade espacial de estudantes estrangeiros que buscam a qualificação de sua formação no Brasil. Vale salientar que essa modalidade tem apresentado forte tendência de crescimento, como indicam os resultados dos países emissores e receptores, pois, a quantidade de estudantes estrangeiros que está buscando qualificação de sua formação em outro país tem aumentado consideravelmente com o tempo (DESIDÉRIO, 2006).

Há de se ressaltar que a migração internacional de estudantes está ligada predominantemente ao ensino superior (graduação, mestrado e doutorado) (DESIDERIO, 2006). Isto porque é através desse tipo específico de migração que se estabelecem intercâmbios e se adquirem conhecimentos técnicos, científicos e informacionais, além de se fortalecer as relações bilaterais ou multilaterais entre as nações envolvidas no processo migratório, o que pode contribuir significativamente para a melhoria de suas economias.

Além das questões de caráter geopolítico, caracterizadas, sobretudo, pelo estabelecimento de acordos bilaterais e/ou multilaterais, esses fluxos migratórios envolvem também uma série de motivações e aspirações individuais almejadas pelos estudantes migrantes. Dentre os principais fatores intervenientes no ato de migrar, os estudantes levam em consideração a oportunidade de estudar e de viver no exterior, principalmente em razão das dificuldades de acesso à educação superior e ao mercado de trabalho em seus países de origem (DESIDÉRIO, 2006).

A intensificação desse fluxo nos últimos anos provocou uma série de trabalhos. Do ponto de vista temático, podem ser agrupar em dois eixos: os que discutem as imigrações contemporâneas no Brasil e os que abordam as relações de intercâmbio e cooperação educacional dos países dos países de língua oficial portuguesa e dos países da América Latina.

Dentre os trabalhos do primeiro eixo, há de se ressaltar as discussões realizadas por Seyferth (2007), que aborda o panorama das imigrações contemporâneas para o Brasil, considerando principalmente as remessas de imigrantes provenientes da África e da América Latina. Além desta, outra obra que merece destaque é a de Barreto (2001), 
que discute as migrações contemporâneas no Brasil, associadas ao processo de globalização e às mudanças econômicas provocadas pela formação de blocos econômicos. Por outro lado, outra reflexão de natureza conceitual a lembrar é o trabalho desenvolvido por Portes (2004), o qual procura discutir a noção de transnacionalismo enquanto categoria de análise dos processos de mobilidade populacional entre países.

Com relação ao segundo eixo, cabe destacar os seguintes trabalhos: o de Vida (2001), que discute as questões sociopolíticas e raciais que envolvem os estudantes africanos radicados no Brasil; o de Kaly (2001), que aborda o preconceito racial vivenciado pelos estudantes africanos ao se instalar no Brasil; o de Subhuana (2005), que faz uma análise da realidade social dos estudantes moçambicanos, moradores no Rio de Janeiro; o de Gusmão (2008), que trata da relação acadêmica entre Brasil e África; e a discussão de Mungoi (2006) sobre a identidade étnica dos estudantes africanos radicados em Porto Alegre. Enquadram-se, nesse mesmo eixo, as discussões sobre os acordos de cooperação internacional na área da educação, como as pesquisas de Gonçalves (2004) e Desidério (2006) sobre o Programa de Estudante-Convênio de Graduação (PEC-G), e o estudo desenvolvido por Grassi (2008) acerca das identidades dos jovens cabo-verdianos radicados em Portugal.

Embora a literatura científica sobre mobilidade internacional na contemporaneidade elenque uma série de fatores para esse processo, há de se destacar que, no contexto da mobilidade motivada por estudo, os trabalhos acabam convergindo para um mesmo conjunto de causas. Assim, as aspirações dos estudantes estão diretamente ligadas à busca de melhores condições de vida; com isso, a educação tem se constituído como um dos mecanismos de fortalecimento do capital humano dessas sociedades em seu processo de intercâmbio com outras realidades. Assim, ao interagir na busca de conhecimentos, os estudantes acabam adquirindo maior capacidade de intervenção em seus países de origem e ascensão social ao regressar após a conclusão do curso (GONÇALVES, 2004; MUNGOI, 2006). Adquirida a qualificação acadêmica e profissional que lhes permitirá melhorias em suas condições sociais, esses estudantes poderão contribuir de forma significativa para o desenvolvimento econômico e social de seus países de origem. Tal perspectiva permite constatar que as instituições e programas 
de apoio e formação avançada destes estudantes têm a expectativa de que eles possam utilizar as capacidades técnicas e intelectuais adquiridas para assumir posições de responsabilidade em universidades, centros de investigação, governo, ONGs e no setor privado de seus respectivos países (GONÇALVES, 2004).

\section{Ações governamentais de incentivo à migração de estudantes}

A internacionalização do conhecimento através das universidades é uma prática que vem desde a Idade Média, com a criação das primeiras escolas europeias. Nelas existiam professores de diferentes lugares, constituindo comunidades internacionais em busca de um objetivo em comum: o conhecimento (STALLIVIERI, 2003). Para a sociedade brasileira, esse híbrido cultural - internacional - de conhecimento e relações nas universidades ocorreu um pouco mais tarde. A presença de estudantes estrangeiros no Brasil e a saída de brasileiros com fins educacionais já acontecia no País desde o início do século XX, mas de forma muito esporádica. Segundo o Ministério da Educação e Cultura (BRASIL, 2014), no ano de 1917 se registrou a presença de estudantes brasileiros no Uruguai; em 1919, estudantes argentinos, chilenos, paraguaios e uruguaios realizavam cursos de nível superior no Brasil e em instituições militares, como a Escola Militar e a Escola Naval.

A partir da aproximação de acordos culturais firmados, entre eles com a Bolívia, registrou-se um contingente de estudantes provenientes dessa nação para o Brasil em 1941. Com a II Guerra Mundial, aconteceu também uma maior aproximação do Brasil com países latino-americanos, o que vem a culminar com um intercâmbio estudantil entre as nações dessa região (BRASIL, 2014).

No decorrer dos anos, o contingente de estudantes estrangeiros foi crescendo, tornando-se necessário um processo administrativo aprimorado. Isto se deu com a criação dos convênios de cooperação cultural bilateral, com vistas a facilitar o ingresso nas instituições de ensino superior (IES) dos estudantes dos países associados. Daí vem a denominação de estudante-convênio, que, segundo o Ministério da Educação e Cultura 
(BRASIL, 2014), diz respeito a uma seleção por via diplomática, com fundamento em convênios (acordos) bilaterais do Brasil com outros países, especialmente os latinoamericanos e africanos.

A partir de então - dos acordos bilaterais e multilaterais de cooperação internacional -, começavam a funcionar de forma institucional oportunidades de qualificação profissional para os estudantes através de intercâmbio educacional nos cursos de graduação, oferecidos pelas universidades brasileiras. Assim, o Programa de Estudantes-Convênio de Graduação (PEC-G) se constituiu em “[...] um dos instrumentos de cooperação educacional, que o Governo brasileiro oferece a outros países em vias de desenvolvimento, especialmente da África e da América Latina" (BRASIL, 2014).

O PEC-G tem origem na década de 1920, mas firmado em protocolos a partir da década de 1960, período em que tal cooperação começa a ganhar corpo enquanto programa de intercâmbio de estudantes. A partir de 1964, verifica-se um processo de administração do PEC-G por dois ministérios: o Ministério das Relações Exteriores (MRE) e o Ministério da Educação e Cultura (MEC); este último, com a participação efetiva a partir de 1967, em função da criação do primeiro protocolo. No entanto, algumas mudanças foram verificadas no programa; dentre elas, a criação da cláusula 2, que limitava acesso ao programa apenas aos países latino-americanos.

Em 1974 é assinado o segundo protocolo, que exigia maior eficiência dos agentes administradores do programa, em função do aumento da demanda por alunos estrangeiros. Nessa nova fase, foram introduzidas algumas alterações, como a cláusula que expandia a outros países, além dos latino-americanos, a oportunidade de participação como conveniados. Também é importante ressaltar a prioridade com o aprendizado da língua portuguesa, pois foi adicionado um termo (já em 1981) ao Protocolo de 1974, que demonstrava preocupação com tal situação "[...] enfatizando a necessidade do ensino de Português para Estudantes Estrangeiros nas Universidades Brasileiras [...]" (BRASIL, 2014).

Em 10 de novembro de 1986, foi assinado mais um protocolo, com o objetivo de enfatizar algumas cláusulas acerca da preocupação com a longa permanência dos 
estudantes estrangeiros conveniados no Brasil, uma vez que algumas IES interpretavam de forma equivocada diversas cláusulas. Ainda com o objetivo de aperfeiçoar o programa, mais dois protocolos foram assinados, um em 1993 e outro em 1998, com a adição normativa de caráter administrativo. De acordo com o Ministério da Educação e Cultura (MEC, 2000), o programa é atualmente regido pelo Decreto Presidencial n. 7.948, publicado em 2013, que confere maior força jurídica ao regulamento do PEC-G.

Esses protocolos, a partir do Programa Estudante - Convênio (PEC-G) -, conferem aos países conveniados oportunidades de desenvolvimento via educação, uma vez que:

[...] representa uma forma de incrementar uma aliança mundial ao desenvolvimento; ou seja, como pacto social global, os países em desenvolvimento, por indicação da Declaração do Milênio, aprovada pelas Nações Unidas, deverão, pelo compromisso do convênio, estar se coletivizando em prol de seu desenvolvimento, pela educação, pela transferência de tecnologia e de maiores oportunidades de qualificação de recursos humanos jovem, que vive em um país em desenvolvimento (DESIDÉRIO, 2006).

Diante disso, o crescimento do Programa tem acontecido gradativamente, segundo o Ministério das Relações Exteriores/Divisão de Temas Educacionais (DCE); isso porque o número de estudantes selecionados pelo programa superou as seis mil inscrições só na última década. A África é o continente de origem da maioria dos estudantes. Cabo Verde, Guiné-Bissau e Angola são os países com maior número de estudantes inscritos nesse período. Já o número de países participantes do programa é de 56, sendo 24 africanos, 25 americanos e 7 asiáticos. Os cursos que apresentaram maior demanda foram os seguintes: letras, comunicação social, administração, ciências biológicas e pedagogia.

De acordo com Desidério (2006), é vital se pensar nos países independentemente de seu nível de desenvolvimento, de forma coletiva, a partir de ações que possam priorizar o desenvolvimento social, profissional e econômico de cada um. O progresso socioeconômico dessas nações se torna viável em função dos convênios, objetivando a qualificação de pessoal através de investimentos e parcerias educacionais. 


\section{Perfil sociodemográfico dos estudantes estrangeiros radicados no Brasil}

A análise do perfil sociodemográfico dos estudantes estrangeiros radicados no Brasil considerou os impactos da migração sobre a família, os traços culturais e outras estruturas sociais. No caso do estudante estrangeiro, utilizaram-se, para a análise e a caracterização do perfil sociodemográfico, as variáveis idade, sexo, raça, instituições de ensino superior por região do Brasil, categoria administrativa, áreas do conhecimento e origem do migrante. Além disso, buscou-se destacar o PEC-G por ser um programa permanente e significativo dentro do contexto brasileiro. Ressalte-se, ainda, que os dados se referem ao Censo do Ensino Superior 2010, razão que explica por que só se consideram as pessoas que se encontravam na condição de estudante estrangeiro no momento do levantamento.

A seleção realizada pelos convênios procura considerar como critério de escolha a idade do candidato que está pleiteando a vaga. Usando como exemplo os estudantes estrangeiros selecionados via PEC-G, percebe-se que a maioria tem entre 20 e 31 anos, assim como os estudantes selecionados de outras formas.

Quando observada a declaração de raça/cor, percebe-se que, tanto no caso do PEC-G, quanto nos demais tipos de ingresso, a informação é indisponível. Entretanto, pode-se perceber, entre as informações disponíveis, uma tendência maior à declaração de raça/cor preta entre os estudantes do PEC-G, enquanto que os demais tipos de ingresso apresentam maioria branca. 
Migrações internacionais motivadas por estudo: uma análise sociodemográfica dos estudantes estrangeiros radicados no Brasil

Ricardo Ojima - Moisés Alberto Calle Aguirre - Bruno Lopes da Silva - William de Mendonça Lima

Tabela 1 - Estudantes estrangeiros radicados no Brasil (2010)

\begin{tabular}{|c|c|c|c|c|}
\hline \multirow{2}{*}{ Categoria } & \multicolumn{2}{|c|}{ PEC - G } & \multicolumn{2}{|c|}{ Outros convênios e formas de ingresso } \\
\hline & $\mathbf{N}$ & $\%$ & $\mathbf{N}$ & $\%$ \\
\hline Idade & 1.872 & 100 & 13.529 & 100 \\
\hline 14 a 19 & 76 & 4,1 & 1.180 & 8,7 \\
\hline 20 a 25 & 1.282 & 68,5 & 6.177 & 45,7 \\
\hline 26 a 31 & 472 & 25,2 & 2.720 & 20,1 \\
\hline 31 e mais & 42 & 2,2 & 3.452 & 25,5 \\
\hline Raça/Cor & 1.872 & 100 & 13.529 & 100 \\
\hline Inf. Indisponível & 1.089 & 58,2 & 9.576 & 70,8 \\
\hline Branca & 133 & 7,1 & 2.193 & 16,2 \\
\hline Preta & 576 & 30,8 & 1.012 & 7,5 \\
\hline Parda e outras & 74 & 4,0 & 748 & 5,5 \\
\hline Sexo & 1.872 & 100 & 13.529 & 100 \\
\hline Masculino & 960 & 51,3 & 6.989 & 51,7 \\
\hline Feminino & 912 & 48,7 & 6.540 & 48,3 \\
\hline Grande Região & 1.862 & 100 & 13.527 & 100 \\
\hline Norte & 47 & 2,5 & 274 & 2,0 \\
\hline Nordeste & 383 & 20,6 & 1.480 & 10,9 \\
\hline C. Oeste & 134 & 7,2 & 1.100 & 8,1 \\
\hline Sudeste & 955 & 51,3 & 7.869 & 58,2 \\
\hline Sul & 343 & 18,4 & 2.804 & 20,7 \\
\hline Categoria Administrativa & 1.872 & 100 & 13.529 & 100 \\
\hline Pública Federal & 1.154 & 61,6 & 2.394 & 17,7 \\
\hline Pública Estadual & 355 & 19,0 & 823 & 6,1 \\
\hline Pública Municipal & 10 & 0,5 & 99 & 0,7 \\
\hline Privada com fins lucrativos & 33 & 1,8 & 4.043 & 29,9 \\
\hline Privada sem fins lucrativos & 320 & 17,1 & 6.170 & 45,6 \\
\hline Grande Área do Conhecimento & 1.872 & 100 & 13.529 & 100 \\
\hline Ciências Humanas & 774 & 41,3 & 7.780 & 57,5 \\
\hline Ciências Exatas e Tecnológicas & 622 & 33,2 & 3.995 & 29,5 \\
\hline Ciências Biológicas & 476 & 25,4 & 1.754 & 13,0 \\
\hline
\end{tabular}

Fonte: Instituto Nacional de Estudos e Pesquisas Educacionais Anísio Teixeira, 2010.

Com relação a sexo, a proporção de estudantes não difere entre o sexo feminino e masculino; da mesma forma ocorre quando se compara o PEC-G com as outras formas de convênio (Tab. 1).

Se há uma diferenciação regional, também há uma diferenciação de caráter administrativo, pois os maiores percentuais de estudantes PEC-G foram identificados nas IES públicas federais (61\%) e estaduais (19\%), enquanto os estudantes inseridos nos outros 
tipos de convênios estão matriculados, com mais frequência (75\%), nas universidades privadas, com e sem fins lucrativos.

Com relação às áreas de conhecimento, a análise dos dados mostrou que 41\% deles se encontram na área de ciências humanas; $33,2 \%$ nas áreas de ciências exatas e tecnológicas e 25,4\% são da área de ciências biológicas, no caso dos estudantes PEC-G. Entre os estudantes que não fazem parte do PEC-G, constatou-se que a área de ciências humanas concentra 57\% desses discentes; a área de ciências exatas e tecnológica, 29\%; as ciências biológicas registram 13\% do total de estudantes dessa área.

Outra variável de grande relevância para a compreensão dos fluxos de estudantes estrangeiros para o Brasil é a área de origem desses fluxos, ou seja, os países de onde são originários. A área de origem, caracterizada como ponto de difusão dos fluxos migratórios, pode ser entendida a partir de dois enfoques conceituais: a) a área de residência em início do intervalo migratório; ou b) a área de residência a partir da qual se deu o último deslocamento. No caso da área de destino, essa discussão, especificamente, diz respeito a uma única unidade geográfica de análise, que se refere ao território brasileiro, visto que as correntes migratórias analisadas se dirigem para várias regiões do País (ONU, 1980).

É relevante, no caso da migração internacional, caracterizar os países participantes do processo, pois, em qualquer dos estudos, existem informações sobre lugares de origem e lugares de destino. A partir delas, é possível investigar as forças responsáveis pela gênese do deslocamento, bem como entender de forma mais detalhada o processo de integração e reorganização espacial dos países envolvidos (VIGNOLI, 2011; SOUCHAUD e FUSCO, 2012). 

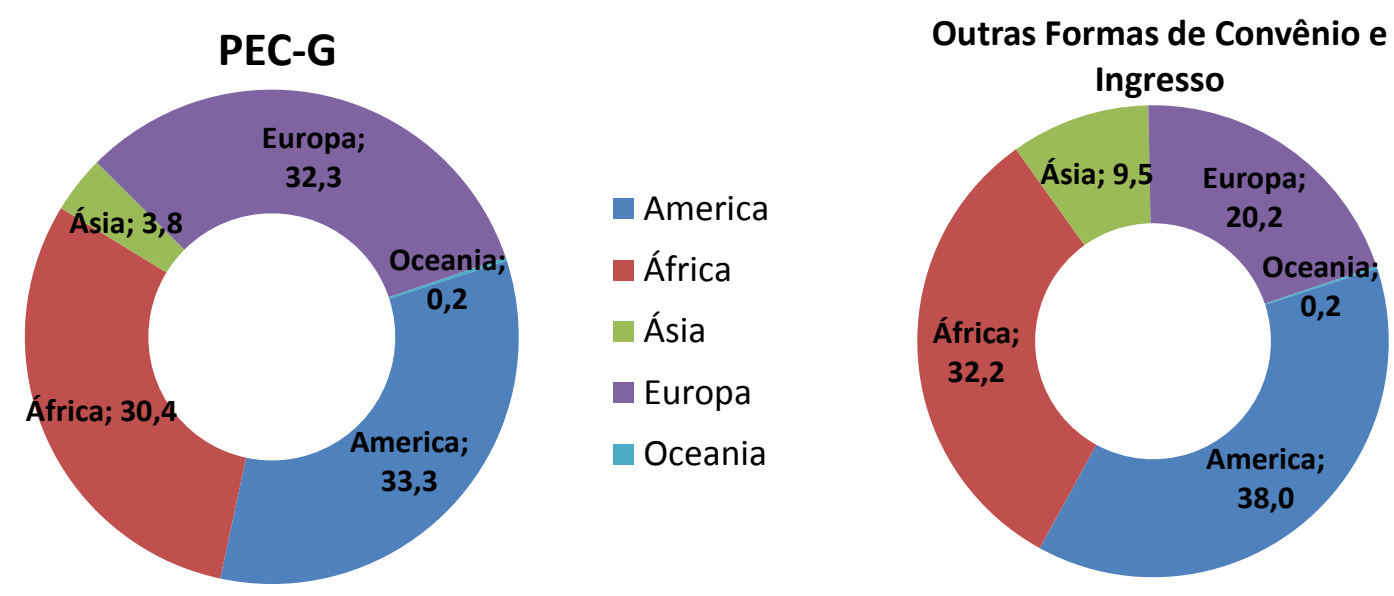

Fonte: Instituto Nacional de Estudos e Pesquisas Educacionais Anísio Teixeira, 2010.

Com base nessas premissas, convém analisar as características desse fluxo migratório de estudantes estrangeiros (participantes do PEC-G e outros convênios e programas de intercâmbio educacional), isto é, qual a participação relativa de cada continente nesse processo de envio de estudantes ao Brasil. Neste sentido, os dados expressos pelo gráfico 1 representam, percentualmente, a participação de cada continente nesse processo de migração, com base nos dados do Censo do Ensino Superior (BRASIL, 2010).

A partir da análise do gráfico 1, percebe-se, em termos percentuais, que os continentes que mais contribuem para a migração de estudantes estrangeiros para o Brasil são a América e a África. De acordo com Desidério (2006), uma provável explicação para o fato são as prioridades estabelecidas pelo Brasil no processo de cooperação com os países africanos de língua portuguesa (Palop) e com os países da América Latina, Caribe e Timor Leste, tendo em vista o estabelecimento de relações bilaterais e multilaterais.

Essas prioridades são legitimadas principalmente através da atuação do PEC-G que, a partir da seleção de alunos dos Palop e da América Latina, visa a fortalecer as 
relações de cooperação e as relações bilaterais. Entretanto, a atuação do PEC-G se restringe a esses dois recortes espaciais (Palop e América Latina); por esse motivo, ao se considerar a dinâmica do processo em escala mundial, incluindo todos os continentes, muitas dessas regiões não são contempladas pelo convênio PEC-G. Neste sentido, o mapa 1 traz informações sobre a origem dos estudantes estrangeiros radicados no Brasil em 2010, incluindo os conveniados e os não conveniados. A análise do mapa 1 evidencia que muitos países apresentam uma contribuição pouco significativa no que se refere ao envio de estudantes estrangeiros para o Brasil, o que requer uma ampliação das relações de cooperação internacional na área da educação pela ampliação e criação de convênios. Por outro lado, há países que fornecem uma quantidade substancial de estudantes como: Argentina, Angola, Guiné Bissau, Cabo Verde e Portugal, os quais mantêm relação de intercâmbio estudantil com o Brasil através do PEC-G e outros programas de incentivo à internacionalização educacional.

Angola é o país que apresenta destacadamente o maior percentual no Brasil, com 12,5\% de todos os estudantes registrados no Censo do Ensino Superior 2010. O destaque de Angola pode ser percebido em razão de este país apresentar quase o dobro do percentual de estudantes estrangeiros do que ocupa o segundo lugar neste ranking, Cabo Verde (6,9\%), seguido de perto pela Argentina (6,3\%), por Guiné Bissau (6,2\%) e Portugal (6\%). Estes cinco países, juntos, correspondem a $38 \%$ de todos os estudantes estrangeiros identificados no Censo do Ensino Superior 2010. É interessante registrar que o convênio difere muito de país para país, pois a Angola - que integra a lista de países participantes dos PEC - possui apenas 10\% dos estudantes sob este convênio. Para Cabo Verde e Guiné Bissau, esta proporção é relativamente elevada, com $52 \%$ e $44 \%$ de estudantes via PEC-G, respectivamente. 
Mapa 1 - Origem dos estudantes estrangeiros (convênio PEC-G) radicados no Brasil

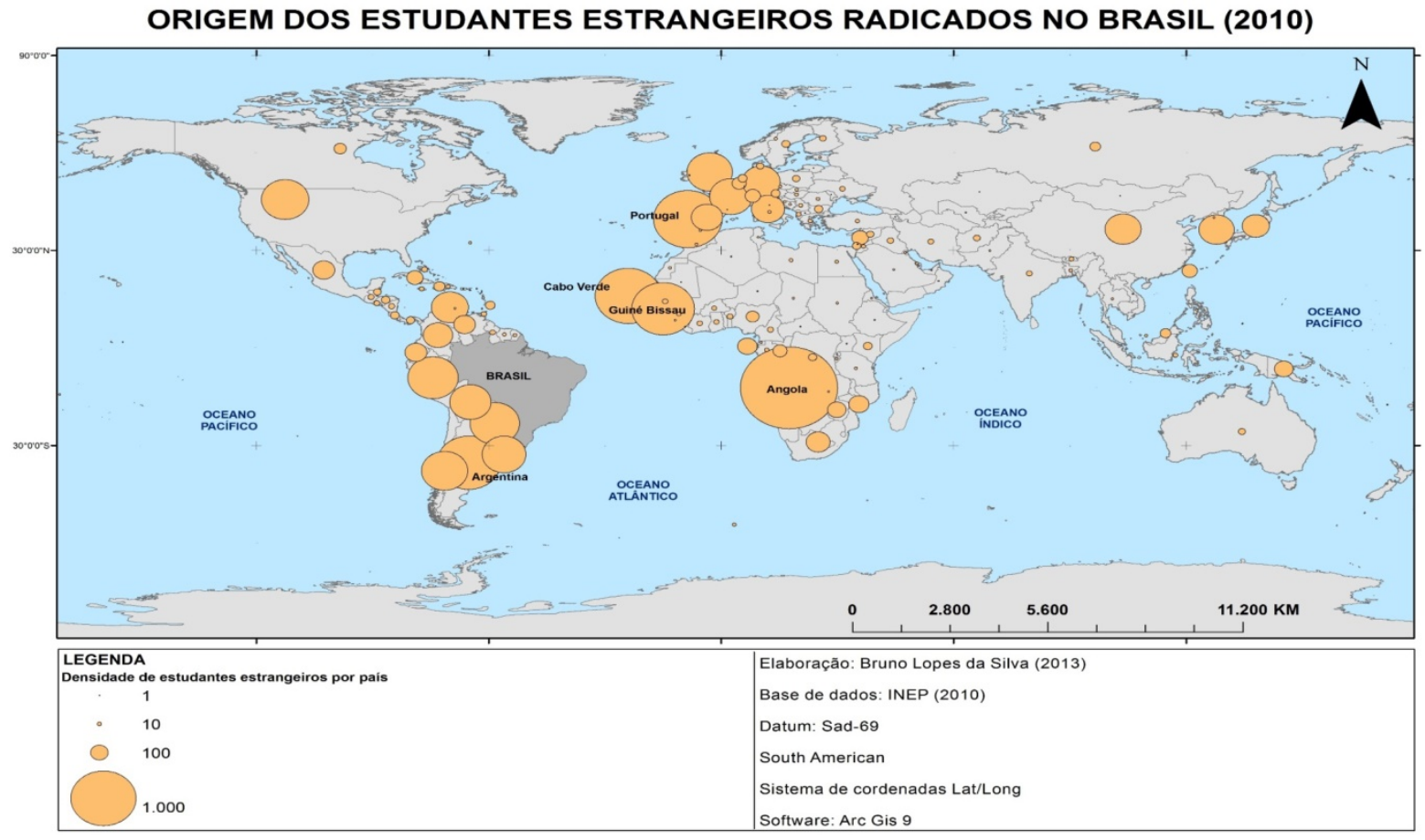

Fonte: Instituto Nacional de Estudos e Pesquisas Educacionais Anísio Teixeira, 2010.

O que se percebe, ao analisar os países de origem destes estudantes, é a estreita ligação entre estudantes latino-americanos e africanos. Estes últimos, ex-colônias portuguesas, são fruto de acordos bilaterais no âmbito educacional (SEYFERTH, 2007).

No caso dos países latino-americanos, além da proximidade geográfica, outro elemento facilitador da integração tem sido a criação dos blocos econômicos, mais precisamente o Mercado Comum do Sul (Mercosul). Com o advento desse bloco, os países que o integram passaram a apresentar relações de intercâmbio mais intensas, principalmente Brasil, Paraguai, Uruguai e Argentina (DESIDÉRIO, 2006).

Além das questões de cunho geopolítico e econômico, como a criação de um bloco econômico, outros fatores têm influenciado esse processo migratório, como a existência de "raízes históricas e culturais comuns" (DESIDÉRIO, 2006, p. 51). Esta premissa é válida não apenas para os países da América, mas também para os países 
africanos. No caso dessas nações, uma das principais motivações que levam os seus estudantes a escolher o Brasil para desenvolver os estudos no ensino superior é justamente o fato de terem o português como língua oficial, assim como no Brasil.

De acordo com Subhuana (2005), o que se percebe é que, na hora de escolher um país para prosseguir os estudos, o Brasil acaba apresentando vantagens comparativas por conta das especificidades históricas, sociais, econômicas, educacionais e culturais em comum com outras nações do mundo, como as africanas e sul-americanas. Além disso, a língua desempenha um papel fundamental nessa seleção, pois a exigência por exames de proficiência em língua inglesa, por exemplo, tendem a dificultar o ingresso de estudantes nas principais universidades do mundo. De fato, o Brasil se colocaria no contexto internacional de educação superior como um importante polo de atração para países em situação de desenvolvimento econômico menos favorável.

\section{Considerações finais}

A partir do que foi apresentado - mobilidade internacional de estudantes -, conseguiu-se identificar uma série de fatores sociodemográficos que influem na dinâmica de realização desse tipo de fluxo, apresentando características diferenciadas em relação ao que tradicionalmente se coloca como principal motivação para migrar, o trabalho.

Cabe ressaltar, em escala internacional, a forte conotação geopolítica da mobilidade de estudantes, visto que é a partir do estabelecimento desses intercâmbios que os países fortalecem os acordos de cooperação bilateral entre si. Porém, o estabelecimento desses intercâmbios depende da existência de convênios entre os países, como o PEC-G, que visa expressamente a que estudantes de outros países tenham a oportunidade de se graduar no Brasil. No caso dos estudantes não contemplados por esse convênio, eles acabam se inserindo em outras ações de natureza similar, ou vem para o Brasil por conta própria.

Considerando a presença de estudantes estrangeiros em várias universidades do Brasil, um dos pontos primordiais para a compreensão mais aprofundada dessa questão diz respeito a seu perfil sociodemográfico. Os dados do Censo do Ensino Superior do ano 
de 2010 demonstraram que há uma predominância de estudantes da faixa etária compreendida entre 20 e 31 anos, não havendo, entre eles, grande diferenciação do ponto de vista da composição por sexo, ou seja, há um verdadeiro equilíbrio na quantidade de homens e mulheres.

Em termos espaciais, a distribuição desses estudantes estrangeiros apresenta grande diferenciação, tanto em relação às regiões do Brasil, quanto em termos continentais. Isto porque os principais pontos de origem desses fluxos são os países da América Latina e da África, mais precisamente Argentina, Angola, Guiné Bissau e Cabo Verde.

Cabe ressaltar que as opções oferecidas aos estudantes estrangeiros via PEC-G derivam da indicação dos cursos de graduação das instituições públicas em proporção ao número de vagas determinado no convênio. Isto explica o perfil sociodemográfico peculiar apresentado pelos estudantes estrangeiros radicados no Brasil, que permite enquadrá-los em uma tipologia ou categorização específica, visto que as correntes migratórias predominantes são as de países que têm como idioma oficial o português.

Notou-se, ainda, que há diferenciações sociodemográficas quando se comparam os estudantes do PEC-G com os estudantes que não pertencem ao programa. Conclui-se, portanto, que os convênios de cooperação educacional influem na decisão do estudante no momento de escolher um país para estudar de maneira diferencial de acordo com o país de origem. Além disso, em escala nacional, notou-se uma considerável diferenciação do perfil desses estudantes, variando de acordo com as regiões, com a categoria administrativa das IES e com os convênios existentes. Neste sentido, apesar de fazerem parte de uma mesma categoria de análise, é pertinente afirmar que essa população apresenta características sociodemográficas diferenciadas e que desdobramentos migratórios de caráter permanente podem surgir a partir dessa primeira incursão no território brasileiro. 


\section{Referências}

ABAD, Rocío García. Las redes migratorias entre el origen y la Ría de Bilbao a finales del siglo: una aproximación metodológica. Revista de Demografía Histórica, v.20 n.01, p. 21-5, 2002, Disponível em: < http://www.adeh.org/?q=es/search/node/ABAD> Acesso em: 10 fev. 2014.

BAENINGER, Rosana. O Brasil no contexto das migrações internacionais da América Latina. In: AUTOR. Populações e políticas sociais no Brasil: os desafios da transição demográfica e das migrações internacionais. Brasília: Centro de Gestão e Estudos Estratégicos, 2008.

BARRETO, Luiz Paulo Teles Ferreira. Considerações sobre a imigração no Brasil contemporâneo. In: CASTRO, Mary Garcia (Coord.). Migrações Internacionais: contribuições para políticas. Brasília: Comissão Nacional de População e Desenvolvimento, 2001.

BRASIL. Ministério da Educação. Manual do Estudante: convênio de graduação. Disponível em <http://portal.mec.gov.br/sesu/arquivos/pdf/CelpeBras/manualpec-g>Acesso em: jan. 2014.

BRASIL. Ministério da Educação. Instituto Nacional de Estudos e Pesquisas Educacionais Anísio Teixeira Microdados do censo da educação superior. Brasília, 2010.

BRITO, Fausto. As migrações internas no Brasil: um ensaio sobre os desafios teóricos recentes. Textos para Discussão n. 366, Belo Horizonte: UFMG/Cedeplar, 2009.

DESIDÉRIO, Edilma de Jesus. Migração internacional com fins de estudo: o caso dos africanos do programa estudante-convênio de graduação em três universidades públicas no Rio de Janeiro. 2006. Dissertação (Mestrado em Estudos Populacionais e Pesquisas Sociais) - Instituto Brasileiro de Geografia e Estatística (IBGE), Rio de Janeiro, 2006.

GONÇALVES, Sandra Marisa Martins Ramos. A política educativa de envio de estudantes para instituições de ensino externas como estratégia de desenvolvimento: o caso africano. 2004. Dissertação (Mestrado em desenvolvimento e cooperação internacional) - Instituto Superior de Economia e Gestão - Universidade Técnica de Lisboa, 2004.

GRASSI, Marzia. Identidades plurais na Europa contemporânea: auto-percepções e representações nos jovens de origem africana em Portugal. In: GÓIS, Pedro. Comunidade(s) cabo-verdiana(s): as múltiplas faces da imigração cabo-verdiana. Lisboa: Alto Comissariado para a Imigração e Diálogo Intercultural (ACIDI, I.P.), 2008. 
GUSMÃO, Neusa Maria Mendes de. África e Brasil no mundo acadêmico: diálogos cruzados. In: COLÓQUIO SABER E PODER, 2008. Anais... Campinas : Focus : Unicamp, 2008.

KALY, Alain Pascal. Os estudantes africanos no Brasil e o preconceito racial. In: CASTRO, Mary Garcia (Coord.). Migrações internacionais: contribuições para Políticas. Brasília: Comissão Nacional de População e Desenvolvimento, 2001.

LEE, Everett S. Uma teoria sobre migração. In: MOURA, Hélio A. de. Migração Interna: textos selecionados. Fortaleza: Setor de documentação e Biblioteca do Banco do Nordeste do Brasil, 1980.

MARTINE, George. Adaptação dos migrantes ou sobrevivência dos mais fortes? In: MOURA, Hélio A. de (Coord.). Migração interna: textos selecionados. Fortaleza: Setor de documentação e biblioteca do Banco do Nordeste do Brasil, 1980.

MUNGOI, Dulce Maria Domingos Chale João. O mito atlântico: relatando experiências singulares de mobilidade dos estudantes africanos em Porto Alegre no jogo de construção e reconstrução de suas identidades étnicas. 2006. Dissertação (Mestrado em Antropologia Social) - Programa de Pós-graduação em Antropologia Social da Universidade Federal do Rio grande do Sul. Porto Alegre, 2006.

OLIVEIRA, Kléber Fernandes de; JANNUZZI, Paulo de Martino. Motivos para migração no Brasil e retorno ao Nordeste: padrões etários, por sexo e origem/destino. Revista São Paulo em Perspectiva, v. 19, n. 4, p. 134-143, out./dez. 2005. Disponível em: <http://www.seade.gov.br/produtos/spp/>. Acesso em: 21 mai. 2014.

ONU. Conceitos básicos, definições e mensuração da migração interna. In: MOURA, Hélio A. de. Migração Interna: textos selecionados. Fortaleza: Setor de documentação e biblioteca do Banco do Nordeste do Brasil, 1980.

PORTES, Alejandro. Convergências teóricas e dados empíricos no estudo do transnacionalismo imigrante. Revista Crítica de Ciências Sociais, 69, Outubro, p.73-93, 2004. Disponível em: <www.ces.uc.pt/rccs/includes/download> Acesso em: 17 maio. 2014.

RIGOTTI, José Irineu Rangel. Análise das migrações no Brasil a partir de dados censitários. Curso introdutório, 3 de jun. de 2013. 18 f. Notas de aula. Slides.

SANTOS, Mauro Augusto dos; BARBIERI, Alisson Flávio; CARVALHO, José Alberto Magno de et al. Migração: uma revisão sobre algumas das principais teorias. Belo Horizonte: UFMG/Cedeplar, 2010. 
SEYFERTH, Giralda. Os estudos da imigração no Brasil: notas sobre uma produção multidisciplinar. In: SEYFERTH, Giralda. ; PÓVOA, Helion; ZANINI, Maria Catarina (Orgs.). Mundos em movimento: ensaios sobre migrações. Santa Maria: Ed. UFSM, 2007.

SOUCHAUD, Sylvain; FUSCO, Wilson. População e Ocupação do Espaço: O Papel das Migrações no Brasil. REDES - Rev. Des. Regional, Santa Cruz do Sul, v. 17, n. 2, p. 5-17, mai./ago. 2012.

STALLIVIERI, Luciane. O Processo de internacionalização nas Instituições de Ensino Superior. Educação Brasileira, Brasília, v. 24, n.48-49, p. 35-57, 2003.

SUBUHANA, Carlos. Estudar no Brasil: imigração temporária de estudantes moçambicanos no Rio de Janeiro. 2005. Tese (Doutorado em Serviço Social) - Universidade Federal do Rio de Janeiro, Escola de Serviço Social, Rio de Janeiro, 2005.

VIDA, Samuel Santana. Africanos no Brasil: ameaça ao paraíso racial. In: CASTRO, Mary Garcia (Coord.). Migrações internacionais: contribuições para Políticas. Brasília: Comissão Nacional de População e Desenvolvimento, 2001.

VIGNOLI, Jorge Rodriguez. Que definições, que teorias, que fontes e que metodologias precisamos para o estudo da migração interna na atualidade. In: CUNHA, José Marcos Pinto da. (Org.). Mobilidade espacial da população: desafios teóricos e metodológicos para o seu estudo. Campinas: Núcleo de Estudos Populacionais - NEPO/Unicamp, 2011. 
Migrações internacionais motivadas por estudo: uma análise sociodemográfica dos estudantes estrangeiros radicados no Brasil

Ricardo Ojima - Moisés Alberto Calle Aguirre - Bruno Lopes da Silva - William de Mendonça Lima

Recebido em: 14/03/2014 Aprovado em: 16/05/2014 